\title{
Diverticular Disease: An Update on Pathogenesis and Management
}

\author{
Mona Rezapour ${ }^{1}$, Saima $\mathrm{Ali}^{2}$, and Neil Stollman ${ }^{3}$ \\ ${ }^{1}$ Division of Gastroenterology and ${ }^{2}$ Department of Internal Medicine, California Pacific Medical Center, San Francisco, CA, and ${ }^{3}$ Division of \\ Gastroenterology, Alta Bates Summit Medical Center, East Bay Center for Digestive Health, Oakland, CA, USA
}

Diverticular disease is one of the most common conditions in the Western world and one of the most common findings identified at colonoscopy. Recently, there has been a significant paradigm shift in our understanding of diverticular disease and its management. The pathogenesis of diverticular disease is thought to be multifactorial and include both environmental and genetic factors in addition to the historically accepted etiology of dietary fiber deficiency. Symptomatic uncomplicated diverticular disease (SUDD) is currently considered a type of chronic diverticulosis that is perhaps akin to irritable bowel syndrome. Mesalamine, rifaximin and probiotics may achieve symptomatic relief in some patients with SUDD, although their role(s) in preventing complications remain unclear. Antibiotic use for acute diverticulitis and elective prophylactic resection surgery are considered more individualized treatment modalities that take into account the clinical status, comorbidities and lifestyle of the patient. Our understanding of the pathogenesis of diverticular disease continues to evolve and is likely to be diverse and multifactorial. Paradigm shifts in several areas of the pathogenesis and management of diverticular disease are explored in this review. (Gut Liver 2018;12:125-132)

Key Words: Diverticular disease; Symptomatic uncomplicated diverticular disease; Diverticulitis

\section{INTRODUCTION}

Diverticular disease and its complications continue to be a worldwide burden on healthcare systems, and is one of the most common conditions in the Western world. It is the eighth most common outpatient diagnosis in the United States with 2,734,119 total outpatient visits in 2010. ${ }^{1}$ Diverticulitis without hemorrhage accounted for 333,464 emergency department vis- its in 2010 with mortality rate of $0.3 \% .{ }^{1}$ It was estimated that diverticulitis accounted for 216,560 hospital admissions at an aggregate cost of $\$ 2.2$ billion in 2012. ${ }^{1}$ Diverticular disease was the 16th most common cause of death among gastrointestinal, liver and pancreatic diseases in the United States in 2012 with crude death rate of 0.9 per 100,000. ${ }^{1}$ Moreover, it is estimated to account for $\$ 100$ million in medication costs. ${ }^{2}$ Diverticulosis is one of the most common findings on colonoscopy with an increase in prevalence with increasing age. ${ }^{2}$ In this paper, we will review the literature in diverticular disease in regards to newer understandings of its pathogenesis and management.

\section{CLASSIFICATION}

\section{Asymptomatic diverticulosis}

Asymptomatic diverticulosis is often an incidental finding in patients undergoing imaging for other indications. ${ }^{3}$ However, the clinical significance of such findings is unclear as there is no indication for treatment or further follow-up for patients with asymptomatic diverticulosis. ${ }^{3}$

\section{Diverticulitis}

Inflammation of a diverticulum leads to diverticulitis. It can present as either an acute or chronic process. Diverticulitis is the most common complication of diverticulosis, which occurs in about $10 \%$ to $25 \%$ of patients. ${ }^{4}$ The pathophysiology of diverticulitis is the obstruction of the diverticulum sac by fecalith, which by irritation of the mucosa causes low-grade inflammation, congestion and further obstruction. ${ }^{3}$ Diverticulitis may be further classified as uncomplicated and complicated (Fig. 1). Complicated diverticulitis is generally characterized by the formation of abscesses, fistulas, obstruction and/or perforation. ${ }^{3}$ An important consideration in the management of diverticulitis is the decision to hospitalize a patient or not. According to

Correspondence to: Neil Stollman

Division of Gastroenterology, Alta Bates Summit Medical Center, East Bay Center for Digestive Health, 300 Frank H Ogawa Plaza, Suite 450, Oakland, CA 94612, USA

Tel: +1-510-444-3297, Fax: +1-510-444-6421, E-mail: Neil@Stollman.com

Received on November 15, 2016. Revised on January 5, 2017. Accepted on January 5, 2017. Published online May 12, 2017

pISSN 1976-2283 eISSN 2005-1212 https://doi.org/10.5009/gnl16552

@ This is an Open Access article distributed under the terms of the Creative Commons Attribution Non-Commercial License (http://creativecommons.org/licenses/by-nc/4.0) which permits unrestricted non-commercial use, distribution, and reproduction in any medium, provided the original work is properly cited. 
American Society for Colon and Rectal Surgery (ASCRS) several factors weigh in to that decision including failure to tolerate oral intake, pain level, overall comorbidities, and social support at home. ${ }^{5}$

\section{Symptomatic uncomplicated diverticular disease}

In the recent years, there has been an evolution in the taxonomic classification of symptomatic diverticular disease into several distinct types (Fig. 1). These include chronic recurrent diverticulitis, segmental colitis associated with diverticulosis (SCAD) and symptomatic uncomplicated diverticular disease (SUDD)., ${ }^{6,7}$ SUDD is defined as chronic diverticulosis with associated chronic abdominal pain in the absence of acute symptoms of diverticulitis or overt colitis. ${ }^{7}$ There may be an overlap between SUDD and irritable bowel syndrome (IBS) due to similar pathophysiologic mechanisms underlying both disease processes, which includes visceral hypersensitivity. ${ }^{7}$ This was studied by Clemens et al., ${ }^{8}$ where they found that SUDD patient had hyperalgesia in the sigmoid colon with diverticula. SUDD is further compared to IBS in regards to altered colonic motility. Bassotti et al. ${ }^{9}$ demonstrated that patients with diverticulosis have a reduction in the number of colonic interstitial cells of Cajal (ICC) and enteric glial cells even though there was no abnormalities in the enteric neuronal population. They studied ICC due to their role in regulation of intestinal motor function and postulated that with reduction in ICC, there is a decrease in colonic electrical slow wave activity which results in slowed transit. At this time, it is unclear whether SUDD and IBS are on a continuum in terms of their pathophysiology or whether patients with IBS are more likely to have diverticulosis and therefore with chronic abdominal pain be labeled as SUDD.

\section{Segmental colitis associated with diverticulosis}

SCAD is now recognized as a distinct entity. It is characterized by nonspecific segmental inflammation in the sigmoid colon surrounded by multiple diverticula. ${ }^{10}$ It does not necessarily involve the diverticular orifice. ${ }^{11}$ Risk factors include male sex and age over 50 years. ${ }^{10}$ Initial presentation is often rectal bleeding with some presenting with diarrhea and/or abdominal pain. ${ }^{10}$ Freeman ${ }^{12}$ studied the clinical behavior of SCAD in over a 20-year period and noted that all patients had complete clinical and pathological remission of disease even those not treated with oral 5-aminosalicylate. Of importance, is the fact that this process appears to be benign and self-limited. ${ }^{10}$

\section{PATHOGENESIS}

The pathogenesis of diverticular disease is multifactorial and not fully understood. However, several factor including colonic wall structure, colonic motility, genetics, fiber intake, vitamin D levels, obesity and physical activity have been studied and thought to influence the pathogenesis of the disease.

\section{Colonic wall structure and motility}

Diverticula of the colon are mucosal herniations in the colon wall muscle layer through (relatively weaker) points of entry of blood vessels through the colonic wall ${ }^{13}$ and are more commonly found in the sigmoid colon in the Western world. Although its pathogenesis remains poorly elucidated, it is likely to be multifactorial. An early and popular theory as to the etiology

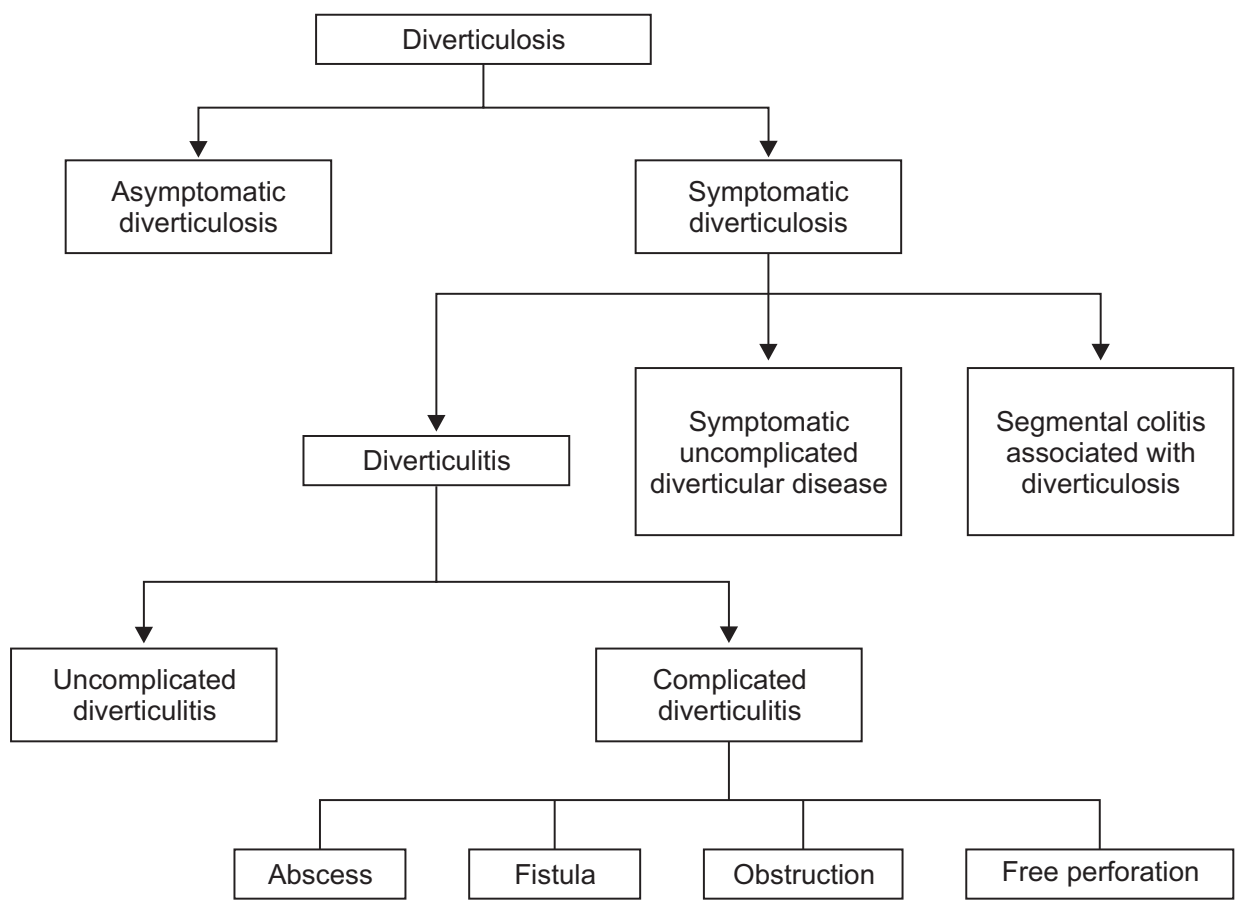

Fig. 1. Classification of diverticular disease. 
of diverticulosis was first described by Burkitt ${ }^{14}$ in 1971, based on his observation that native Africans had a low incidence of diverticular disease. He hypothesized that this was due to a high fiber diet, which would foster shorter transit time through the colon. ${ }^{14,15}$ However, several more recent cross-sectional studies have failed to confirm an association between low dietary fiber intake and an increased risk of diverticulosis. ${ }^{16,17}$

In 2013, Peery et al. ${ }^{17}$ reported that less frequent bowel movements and hard stools were associated with a decreased risk of diverticulosis. In addition, straining or incomplete evacuation were not associated with diverticulosis, both observations arguing against the prevailing paradigm that low dietary fiber is associated with the development of diverticulosis. Painter ${ }^{18}$ was first to hypothesize that constipation created high pressures in the sigmoid colon leading to herniation in the colonic wall. However, motility studies in patients with diverticulosis demonstrate conflicting results. ${ }^{19-25}$ Bassotti et al. ${ }^{19}$ reported significantly increased motility and forceful propulsive activity in patients with diverticular disease as compared to controls. On the other hand, other motility studies including one by Weinreich and Andersen $^{22}$ showed no association between diverticulosis and colonic high-pressure activity.

\section{Genetics}

While the pathogenesis of diverticular disease has largely been thought to be due to environmental risk factors such as diet, more recent epidemiologic data point to the additional contribution of genetic factors in the development of diverticular disease. This is in part supported by the anatomic observation that in Western countries, diverticulosis is most often localized to the left colon, whereas it is predominantly localized in the right colon in Asian countries. ${ }^{26}$ In addition, studies of population migration suggest that despite populations adopting new environmental factors, there may not be subsequent changes in diverticular disease incidence. Several studies confirm the above notion. One study showed that Turkish migrants in the Zaanstreek region of Netherlands have a much lower incidence of diverticulosis than the native Dutch population of $7.5 \%$ compared to $50 \% .^{27}$ Also, in the Japanese population living in Hawaii and eating a more Westernized diet, diverticula remain predominantly right sided. ${ }^{28}$ Most recently, two large twin studies found that genetic factors are a strong contributor to developing diverticular disease. A study of the Swedish Twin Registry found that the odds ratio (OR) of developing diverticular disease if one's co-twin was affected was 7.15 in monozygotic twins as compared to 3.2 for dizygotic twins. ${ }^{29}$ The Danish twin study found a relative risk (RR) for diverticulosis in twin siblings was 2.92 as compared to the general population. ${ }^{30}$ Both studies estimate the contribution of heredity to be roughly $40 \%$ to $50 \%$ (Table 1).

\section{Role of dietary fiber}

As previously mentioned, the prevailing paradigm in the development of diverticulosis focused on low dietary fiber intake resulting in higher intracolonic pressures. ${ }^{15}$ However, this notion has become more controversial. For example, Peery et al. ${ }^{17}$ examined the relationship between bowel habits and dietary fiber intake in the development of asymptomatic diverticulosis and found that less frequent bowel movements and hard stools were associated with a reduced risk of diverticulosis. In addition, there was no association between dietary fiber intake and risk of diverticulosis. ${ }^{16,17}$ Several studies, however, have examined the role of dietary fiber intake in the development of diverticular complications. In 1994, Aldoori et al. ${ }^{31}$ examined the association between dietary fiber and symptomatic diverticular disease and found that a low dietary fiber intake increases the incidence of symptomatic diverticular disease. Furthermore, Crowe et al. ${ }^{32}$ assessed the association between dietary fiber intake with risk of diverticular disease complications. They found that consumption of high fiber diet was associated with lower risk of hospital admissions and death from diverticular disease. ${ }^{32,33}$ Taken together, it appears that the evidence for the role of dietary fiber deficiency in the development of diverticulosis is inconsistent but that there likely exists some benefit to increased fiber intake in the reduction of diverticular disease complications. Based largely on this data, the recent American Gastroenterology Association (AGA) guidelines on diverticulitis overtly suggest a high dietary fiber intake in patients with a history of acute diverticulitis (Table 1). ${ }^{34}$

\section{Role of vitamin D}

The role of vitamin D has recently been explored in diverticular disease. In a retrospective cohort study conducted by Maguire et al., ${ }^{35}$ prediagnostic levels of vitamin D (25-OH) were measured and compared between 9,116 patients with uncomplicated diverticulosis and 922 patients who developed diverticulitis

Table 1. Key Recommendations

\footnotetext{
In addition to dietary fiber intake, genetics plays a role in the pathogenesis of diverticular disease.

Antibiotic use should be selective in acute uncomplicated diverticulitis, consider withholding in mild cases.

Colonoscopy should be performed after resolution of acute diverticulitis if high-quality exam of the colon has not been recently performed.

Fiber intake decreases diverticular disease complications.

NSAIDs should be avoided in patients with a history of diverticulitis; seeds and nuts need not be.
}

NSAIDs, nonsteroidal anti-inflammatory drug. 
requiring hospitalization. The study found a statistically significant higher mean prediagnostic serum vitamin D (25-OH) level in patients with uncomplicated diverticulosis in comparison to patients who required hospitalization for diverticulitis. ${ }^{35}$ These findings were further supported by a second large study that showed an association between low ultraviolet light exposure and diverticulitis. ${ }^{36}$ The findings of this study would suggest that a lower serum vitamin D (25-OH) might confer higher risk of complicated diverticulitis and hint at the possibility of vitamin D deficiency in the pathogenesis of diverticulitis, although this (and any potential role of vitamin D treatment) remains conjecture. Larger cohort studies will be necessary to verify this.

\section{Role of obesity and active lifestyle}

The rate of diverticular disease has increased over the past few decades in conjunction with increasing rates of obesity. Obesity has been often cited as a risk factor for numerous gastrointestinal diseases including diverticulitis. Multiple large prospective studies have shown positive associations between body mass index, waist circumference, and waist-to-hip ratio and risk of diverticulitis. ${ }^{37-40}$ Similar to vitamin D, the pathophysiology of this risk factor is still not clearly defined. Numerous studies have been conducted in determining the effects of obesity on changes in gut microbiota in both human and mice models, in an effort to see if this may explain obesity's contribution to diverticular disease. ${ }^{41-43}$ Further investigation into the shifts in gut microbiota in obese individuals is needed to see if it can explain the increased risk of diverticular disease in this population.

Interestingly, there has been conflicting data on the role of physical activity in decreasing risk of diverticulosis. In Peery et al.'s ${ }^{17}$ study of 2,104 participants, there was no association found between diverticulosis and physical activity. However, other studies have shown that physical activity is associated with fever complications of diverticular disease. ${ }^{38,40}$

\section{NSAIDS/ASPIRIN AND RISK FOR DIVERTICULAR COMPLICATIONS}

Cyclooxygenase inhibitors have a well-known association with increased risk of gastrointestinal bleeding (i.e., ulcers and diverticular) but are also being increasingly recognized as risk factors for diverticulitis and its complications. The strongest data supporting this comes from a meta-analysis examining 11 studies of nonsteroidal anti-inflammatory drug (NSAID) as- sociation with diverticular perforation (OR, 3.4) and 12 studies illustrating NSAID association with diverticular bleeding (OR, 2.6). ${ }^{44}$ This association was also supported by data collected in a large prospective cohort study of 47,210 U.S. men in the Health Professionals Follow-Up Study. ${ }^{45}$ The results of this study showed that regular use of aspirin (greater than or equal to two times per week) had a RR of 1.25 (95\% confidence interval [CI], 1.05 to 1.47 ) of diverticulitis and RR of 1.70 (95\% CI, 1.21 to 2.39) for diverticular bleeding in comparison to nonusers. This association was seen in non-aspirin NSAID users as well (RR, 1.72; $95 \%$ CI, 1.40 to 2.11$).^{39}$ For this reason, the most recent AGA guidelines recommend avoiding non-aspirin NSAIDs (but not avoiding therapeutic aspirin) in patients after acute diverticulitis (Table 1). ${ }^{34}$

\section{MEDICAL TREATMENT}

\section{Antibiotic use in acute diverticulitis}

For decades, antibiotics have been the cornerstone of acute diverticulitis treatment. This was mainly due to the prevailing belief that diverticulitis was due to obstruction of a diverticulum leading to mucosal abrasions, micro-perforation and translocation of bacteria. ${ }^{46}$ However, this view has been challenged with emerging hypotheses focusing on a belief that some subset of acute diverticulitis may be more of an inflammatory process. ${ }^{34}$ In addition, multiple uncontrolled and now two randomized trials have shown no benefit for the use of antibiotics in the management of some patients with uncomplicated diverticulitis. ${ }^{47,48}$ Chabok et al. ${ }^{47}$ reported the first randomized controlled trial investigating the need for antibiotic treatment in acute uncomplicated diverticulitis and found no statistically significant difference in outcome, and suggested that its use should be reserved for the treatment of complicated disease. ${ }^{47}$ In addition, Isacson et $a l^{49}$ recently performed a retrospective population-based cohort study looking at the applicability of a selective "no antibiotic' policy and its consequences in terms of complications and recurrence. In 195 patients with uncomplicated acute diverticulitis, 91.3\% were not treated with antibiotics and were found to have 3.4\% readmission rate. Of these, $2 \%$ developed an abscess. In addition, $12.8 \%$ of patients had recurrence of acute diverticulitis within 1 year. The authors concluded that withholding antibiotics is safe in some patients with acute uncomplicated diverticulitis with low recurrence and complication rates. ${ }^{49}$ Most recently, Daniels et al..$^{50}$ performed a randomized controlled

Table 2. Treatment of Diverticular Disease

\begin{tabular}{ll}
\hline Mesalamine & Does not reduce diverticular recurrence \\
Rifaximin & Does not reduce diverticular recurrence \\
Probiotics & Does not reduce diverticular recurrence \\
Physical activity & Vigorous activity decreases risk of diverticulitis \\
Elective surgery & Not advised for initial episode of acute diverticulitis \\
\hline
\end{tabular}


trial of observation versus antibiotic treatment for a first episode of uncomplicated acute diverticulitis. In 528 patients with computed tomography (CT)-proven uncomplicated acute diverticulitis, they found that there was no prolongation of recovery time in those treated without antibiotics. In addition, there were no significant differences between the observational group and antibiotic treatment group in terms of complicated diverticulitis, ongoing diverticulitis, recurrent diverticulitis, sigmoid resection, readmission, adverse events or mortality. In fact, patients in the observation group had a significantly shorter hospital stay (2 days vs 3 days, $\mathrm{p}=0.006$ ). ${ }^{50}$ Again, this study's findings support the most recent AGA guidelines (in addition to multiple European guidelines), which suggest selective, rather than routine use of antibiotics in patients with acute diverticulitis (Table 1). ${ }^{34,51,52}$

\section{Rifaximin}

Rifaximin is a poorly absorbable oral antibiotic with broad spectrum of action, which has been investigated and used in the treatment of SUDD. ${ }^{53}$ A recent meta-analysis evaluated four prospective randomized studies of 1,660 patients and found that the primary outcome of symptom relief at 1 year was achieved by $64 \%$ of patients in the treatment group of rifaximin as compared to $34.9 \%$ in the control group and this difference was statistically significant. ${ }^{54}$ More concrete outcomes, such as complicated and recurrent diverticulitis were less impressive, and given the immature data, the newest AGA guidelines suggest against the use of rifaximin as an agent to reduce diverticulitis recurrence (Table 2). ${ }^{34}$

\section{Mesalamine}

Since it is believed that low-grade chronic inflammation may play a role in the pathogenesis of SUDD, mesalamine has been investigated in this patient population. ${ }^{55}$ A U.S. randomized trial of 12 weeks of mesalamine after an episode of acute diverticulitis did show improvement in global symptoms at some time points, but was underpowered to evaluate recurrence. ${ }^{56}$ However, Raskin et al. ${ }^{57}$ conducted a larger phase 3 randomized, double-blind, placebo-controlled multicenter trial in 1,182 patients evaluating the efficacy of mesalamine in preventing recurrence of diverticulitis. They found that mesalamine did not reduce the rate of diverticulitis recurrence, time to recurrence, or the number of patients requiring surgery and therefore concluded that mesalamine should not be recommended for prevention of recurrent diverticulitis. Consistent with this large and welldesigned trial, the AGA also recommends against the use of mesalamine for the prevention of diverticulitis recurrence (Table 2). ${ }^{34}$ A recent meta-analysis also found no evidence in support of the use of mesalamine to prevent diverticulitis recurrence. ${ }^{58}$ Whether or not there is a role for this agent in symptom relief in patients with SUDD remains to be clarified.

\section{Probiotics}

Inflammation secondary to fecal stasis in diverticular disease has been suspected to cause changes in the colonic microbiome. Characterization of this microbiome however has been sparse and there is little precise relevant data. A systematic review conducted by Lahner et al. ${ }^{59}$ examined 11 studies in which various probiotics (majority of which were Lactobacillus strains) were used in the treatment of diverticular disease. Upon examination of an overall pool of 764 patients, there appears to be a positive trend in the reduction and/or remission of abdominal symptoms with the implementation of probiotics. Data on prevention of complications and recurrence is limited, however, and the 2015 AGA guidelines recommend against the use of probiotics after acute uncomplicated diverticulitis (Table 2). ${ }^{34}$

\section{Physical activity}

Physical activity has been studied in many gastrointestinal disorders and proposed to reduce risk of colon cancer and other gastrointestinal disorder through decreased transit time, inflammation and/or colon pressure, ${ }^{60,61}$ which are similar mechanisms at play in diverticular disease. Strate et al. ${ }^{37}$ studied 47,228 U.S. males in the Health Professionals Follow-up Study cohort and found that physical activity does decrease the risk of diverticulitis and diverticular bleeding. However this association was only seen with vigorous activity, which included running. In addition, they found that sedentary behaviors were associated with an increased risk of uncomplicated diverticulosis with a RR of $1.29 .^{37}$ This is in line with AGA guidelines that also suggest vigorous physical activity in appropriate patients after acute diverticulitis (Table 2$)^{34}$

\section{SURGICAL TREATMENT}

Previously, the standard convention had been to begin to discuss possible prophylactic resection after a second attack of acute diverticulitis, but this wisdom is changing., ${ }^{5,34}$ The most recent AGA guidelines suggest against elective colonic resection in patients with acute uncomplicated diverticulitis (Table 2). ${ }^{34}$ Rather, they recommend an individualized approach to the surgical management of these patients. This approached is echoed in the most recent ASCRS guidelines as well, ${ }^{5}$ which also supports an individualized approach, rather than any numerical threshold. This shift in paradigm is in part due to several recent studies suggesting that the recurrence rate of diverticulitis and progression to complications are likely lower than previously thought. These studies report recurrence rates in medically managed acute diverticulitis of 13\% to 23\%. ${ }^{62-64}$ In 2010, Eglinton et al. ${ }^{64}$ reported a 5\% rate of complication after an initial attack of uncomplicated diverticulitis. In addition, Shahedi et al. ${ }^{65}$ evaluated the risk of acute diverticulitis among patients with confirmed diagnosis of diverticulosis and found that among 2,222 
patients over an 11-year follow-up period, only roughly 4\% of patients develop acute diverticulitis, even with liberal diagnostic criteria. And lastly, Salem et al. ${ }^{66}$ performed a cost analysis after an episode of diverticulitis to determine the best strategy for management and determined that surgery after the fourth episode of diverticulitis resulted in fewer deaths and was more cost effective in both younger and older patients.

\section{COLONOSCOPY AFTER DIVERTICULITIS}

It is generally accepted practice to perform colonoscopy after the resolution of acute diverticulitis in those candidates where an examination of the colon has not recently been performed in order to exclude a misdiagnosis of colonic neoplasm. ${ }^{34}$ A recent meta-analysis evaluated the yield of colonoscopic evaluation after an episode of acute diverticulitis. They reviewed 11 studies with 1,970 patients and found a pooled proportional estimate of malignancy of $1.6 \% .{ }^{67}$ However, Daniels et al. ${ }^{68}$ recently compared the colonoscopic detection rate of advanced colonic neoplasia in patients with a first episode of acute diverticulitis with patients undergoing initial colorectal cancer (CRC) screening colonoscopy. They found that $6.7 \%$ of patients with acute diverticulitis had advanced colonic neoplasia as compared to 9.1\% of patients undergoing CRC screening with OR of 0.71. They therefore concluded that since the detection of advanced colonic neoplasia does not differ significantly between the above groups that routine colonoscopic follow-up after an uncomplicated acute diverticulitis can be eliminated and those patients can be enrolled in routine CRC screening program. ${ }^{68}$ Lastly, Lau et al. ${ }^{69}$ evaluated the yield of colonoscopy after diagnosis of left-sided diverticulitis, excluding patients that underwent colonoscopy within 1 year of diverticulitis diagnosis. Their findings were significant for prevalence of colorectal cancer of $2.1 \%$ within 1 year after CT-scan diagnosis of acute diverticulitis with an increase in those with abscess, local perforation and fistula as compared to those with uncomplicated disease. Therefore, they recommended routine colonoscopy after a diagnosis of acute diverticulitis if the patient had not had a recent colonoscopic evaluation. ${ }^{69}$ This is echoed in a similar manner in the most recent AGA guidelines. ${ }^{34}$

\section{CONCLUSIONS}

Diverticular disease is a complex disease process with a number of paradigm shifts in recent years in regards to its pathogenesis and management. Much of our accepted understanding of diverticular disease has been challenged, including the role of fiber in etiology, as well as risk factors beyond fiber deficiency, such as genetics, exercise, and perhaps even low vitamin D levels. There is an active search for effective treatments for SUDD, and while nothing is yet strongly data supported, there is evidence that mesalamine, non-absorbable antibiotics, or probiotics, might improve symptoms. There is also now fairly strong data that antibiotics can be used selectively, rather than routinely, in acute diverticulitis, although defining the best candidates for conservative treatment remains unclear. Finally, the role of prophylactic surgical resection is being considered less often, and at a later stage, than previously.

\section{CONFLICTS OF INTEREST}

No potential conflict of interest relevant to this article was reported.

\section{REFERENCES}

1. Peery AF, Crockett SD, Barritt AS, et al. Burden of gastrointestinal, liver, and pancreatic diseases in the United States. Gastroenterology 2015;149:1731-1741.e3.

2. Everhart JE, Ruhl CE. Burden of digestive diseases in the United States part II: lower gastrointestinal diseases. Gastroenterology 2009;136:741-754.

3. Bhucket TP, Stollman NH. Diverticular disease of the colon. In: Feldman M, Friedman LS, Brandt LJ, eds. Sleisenger and Fordtran's gastrointestinal and liver disease: pathophysiology, diagnosis, management. Volume 2. 10th ed. Philadelphia: Elsevier, 2014:1-15.

4. Parks TG. Natural history of diverticular disease of the colon. Clin Gastroenterol 1975;4:53-69.

5. Feingold D, Steele SR, Lee S, et al. Practice parameters for the treatment of sigmoid diverticulitis. Dis Colon Rectum 2014;57:284294.

6. Peery AF, Sandler RS. Diverticular disease: reconsidering conventional wisdom. Clin Gastroenterol Hepatol 2013;11:1532-1537.

7. Strate LL, Modi R, Cohen E, Spiegel BM. Diverticular disease as a chronic illness: evolving epidemiologic and clinical insights. Am J Gastroenterol 2012;107:1486-1493.

8. Clemens CH, Samsom M, Roelofs J, van Berge Henegouwen GP, Smout AJ. Colorectal visceral perception in diverticular disease. Gut 2004;53:717-722.

9. Bassotti G, Battaglia E, Bellone G, et al. Interstitial cells of Cajal, enteric nerves, and glial cells in colonic diverticular disease. J Clin Pathol 2005;58:973-977.

10. Freeman HJ. Segmental colitis associated diverticulosis syndrome. World J Gastroenterol 2016;22:8067-8069.

11. Tursi A, Elisei W, Giorgetti GM, Aiello F, Brandimarte G. Inflammatory manifestations at colonoscopy in patients with colonic diverticular disease. Aliment Pharmacol Ther 2011;33:358-365.

12. Freeman HJ. Natural history and long-term clinical behavior of segmental colitis associated with diverticulosis (SCAD syndrome). Dig Dis Sci 2008;53:2452-2457.

13. Slack WW. The anatomy, pathology, and some clinical features of divericulitis of the colon. Br J Surg 1962;50:185-190

14. Burkitt DP. Epidemiology of cancer of the colon and rectum. Can- 
cer 1971;28:3-13.

15. Painter NS. The cause of diverticular disease of the colon, its symptoms and its complications: review and hypothesis. J R Coll Surg Edinb 1985;30:118-122.

16. Peery AF, Barrett PR, Park D, et al. A high-fiber diet does not protect against asymptomatic diverticulosis. Gastroenterology 2012;142:266-272.e1.

17. Peery AF, Sandler RS, Ahnen DJ, et al. Constipation and a lowfiber diet are not associated with diverticulosis. Clin Gastroenterol Hepatol 2013;11:1622-1627.

18. Painter NS. Diverticular disease of the colon: a disease of the century. Lancet 1969;2:586-588.

19. Bassotti G, Battaglia E, Spinozzi F, Pelli MA, Tonini M. Twentyfour hour recordings of colonic motility in patients with diverticular disease: evidence for abnormal motility and propulsive activity. Dis Colon Rectum 2001;44:1814-1820.

20. Painter NS, Truelove SC, Ardran GM, Tuckey M. Segmentation and the localization of intraluminal pressures in the human colon, with special reference to the pathogenesis of colonic diverticula. Gastroenterology 1965;49:169-177.

21. Parks TG, Connell AM. Motility studies in diverticular disease of the colon. Gut 1969;10:534-542.

22. Weinreich J, Andersen D. Intraluminal pressure in the sigmoid colon: II. patients with sigmoid diverticula and related conditions. Scand J Gastroenterol 1976;11:581-586.

23. Weinreich J, Möller SH, Andersen D. Colonic haustral pattern in relation to pressure activity and presence of diverticula. Scand J Gastroenterol 1977;12:857-864.

24. Leandro PA, Cecconello I, Habr-Gama A, de Olivereira e Silva A, Pontes JF. Gastrointestinal motility in normal subjects and patients with diverticulosis of the colon. Arq Gastroenterol 1984;21:157163.

25. Viebig RG, Pontes JF, Michelsohn NH. Electromanometry of the rectosigmoid in colonic diverticulosis. Arq Gastroenterol 1994;31:135-144.

26. Rajendra S, Ho JJ. Colonic diverticular disease in a multiracial Asian patient population has an ethnic predilection. Eur J Gastroenterol Hepatol 2005;17:871-875.

27. Loffeld RJ. Diverticulosis of the colon is rare amongst immigrants living in the Zaanstreek region in the Netherlands. Colorectal Dis 2005;7:559-562.

28. Stemmermann GN. Patterns of disease among Japanese living in Hawaii. Arch Environ Health 1970;20:266-273.

29. Granlund J, Svensson T, Olén 0, et al. The genetic influence on diverticular disease: a twin study. Aliment Pharmacol Ther 2012;35:1103-1107.

30. Strate LL, Erichsen R, Baron JA, et al. Heritability and familial aggregation of diverticular disease: a population-based study of twins and siblings. Gastroenterology 2013;144:736-742.e1.

31. Aldoori WH, Giovannucci EL, Rockett HR, Sampson L, Rimm EB, Willett WC. A prospective study of dietary fiber types and symptomatic diverticular disease in men. J Nutr 1998;128:714-719.
32. Crowe FL, Appleby PN, Allen NE, Key TJ. Diet and risk of diverticular disease in Oxford cohort of European Prospective Investigation into Cancer and Nutrition (EPIC): prospective study of British vegetarians and non-vegetarians. BMJ 2011;343:d4131.

33. Crowe FL, Balkwill A, Cairns BJ, et al. Source of dietary fibre and diverticular disease incidence: a prospective study of UK women. Gut 2014;63:1450-1456.

34. Stollman N, Smalley W, Hirano I; AGA Institute Clinical Guidelines Committee. American Gastroenterological Association Institute guideline on the management of acute diverticulitis. Gastroenterology 2015;149:1944-1949.

35. Maguire LH, Song M, Strate LE, Giovannucci EL, Chan AT. Higher serum levels of vitamin D are associated with a reduced risk of diverticulitis. Clin Gastroenterol Hepatol 2013;11:1631-1635.

36. Maguire LH, Song M, Strate LL, Giovannucci EL, Chan AT. Association of geographic and seasonal variation with diverticulitis admissions. JAMA Surg 2015;150:74-77.

37. Strate LL, Liu YL, Aldoori WH, Syngal S, Giovannucci EL. Obesity increases the risks of diverticulitis and diverticular bleeding. Gastroenterology 2009;136:115-122.e1.

38. Strate LL, Liu YL, Aldoori WH, Giovannucci EL. Physical activity decreases diverticular complications. Am J Gastroenterol 2009;104:1221-1230.

39. Rosemar A, Angerås U, Rosengren A. Body mass index and diverticular disease: a 28-year follow-up study in men. Dis Colon Rectum 2008;51:450-455.

40. Hjern F, Wolk A, Håkansson N. Obesity, physical inactivity, and colonic diverticular disease requiring hospitalization in women: a prospective cohort study. Am J Gastroenterol 2012;107:296-302.

41. Ly NP, Litonjua A, Gold DR, Celedón JC. Gut microbiota, probiotics, and vitamin D: interrelated exposures influencing allergy, asthma, and obesity? J Allergy Clin Immunol 2011;127:10871094.

42. Ley RE, Bäckhed F, Turnbaugh P, Lozupone CA, Knight RD, Gordon JI. Obesity alters gut microbial ecology. Proc Natl Acad Sci U S A 2005;102:11070-11075.

43. Turnbaugh PJ, Bäckhed F, Fulton L, Gordon JI. Diet-induced obesity is linked to marked but reversible alterations in the mouse distal gut microbiome. Cell Host Microbe 2008;3:213-223.

44. Kvasnovsky CL, Papagrigoriadis S, Bjarnason I. Increased diverticular complications with nonsteriodal anti-inflammatory drugs and other medications: a systematic review and meta-analysis. Colorectal Dis 2014;16:0189-0196.

45. Strate LL, Liu YL, Huang ES, Giovannucci EL, Chan AT. Use of aspirin or nonsteroidal anti-inflammatory drugs increases risk for diverticulitis and diverticular bleeding. Gastroenterology 2011;140:1427-1433.

46. Jacobs D0. Clinical practice: diverticulitis. N Engl J Med 2007;357:2057-2066.

47. Chabok A, Påhlman L, Hjern F, Haapaniemi S, Smedh K; AVOD Study Group. Randomized clinical trial of antibiotics in acute uncomplicated diverticulitis. Br J Surg 2012;99:532-539. 
48. Westwood DA, Eglinton TW. Antibiotics may not improve shortterm or long-term outcomes in acute uncomplicated diverticulitis. Evid Based Med 2013;18:32-33.

49. Isacson D, Andreasson K, Nikberg M, Smedh K, Chabok A. No antibiotics in acute uncomplicated diverticulitis: does it work? Scand J Gastroenterol 2014;49:1441-1446.

50. Daniels L, Ünlü Ç, de Korte N, et al. Randomized clinical trial of observational versus antibiotic treatment for a first episode of CTproven uncomplicated acute diverticulitis. Br J Surg 2017;104:5261.

51. Tursi A, Picchio M, Elisei W, Di Mario F, Scarpignato C, Brandimarte G. Management of patients with diverticulosis and diverticular disease: consensus statements from the 2nd International Symposium on Diverticular Disease. J Clin Gastroenterol 2016;50 Suppl 1:S101-S107.

52. Annibale B, Carabotti M, Cuomo R. Italian guidelines. J Clin Gastroenterol 2016;50 Suppl 1:S44-S46.

53. Papi C, Ciaco A, Koch M, Capurso L. Efficacy of rifaximin in the treatment of symptomatic diverticular disease of the colon: a multicentre double-blind placebo-controlled trial. Aliment Pharmacol Ther 1995;9:33-39.

54. Bianchi M, Festa V, Moretti A, et al. Meta-analysis: long-term therapy with rifaximin in the management of uncomplicated diverticular disease. Aliment Pharmacol Ther 2011;33:902-910.

55. Tursi A, Brandimarte G, Elisei W, et al. Randomised clinical trial: mesalazine and/or probiotics in maintaining remission of symptomatic uncomplicated diverticular disease. A double-blind, randomised, placebo-controlled study. Aliment Pharmacol Ther 2013;38:741-751.

56. Stollman N, Magowan S, Shanahan F, Quigley EM; DIVA Investigator Group. A randomized controlled study of mesalamine after acute diverticulitis: results of the DIVA trial. J Clin Gastroenterol 2013;47:621-629.

57. Raskin JB, Kamm MA, Jamal MM, et al. Mesalamine did not prevent recurrent diverticulitis in phase 3 controlled trials. Gastroenterology 2014;147:793-802.

58. Khan MA, Ali B, Lee WM, Howden CW. Mesalamine does not help prevent recurrent acute colonic diverticulitis: meta-analysis of randomized, placebo-controlled trials. Am J Gastroenterol 2016;111:579-581.

59. Lahner E, Bellisario C, Hassan C, Zullo A, Esposito G, Annibale B. Probiotics in the treatment of diverticular disease: a systematic review. J Gastrointestin Liver Dis 2016;25:79-86.

60. Colditz GA, Cannuscio CC, Frazier AL. Physical activity and reduced risk of colon cancer: implications for prevention. Cancer Causes Control 1997;8:649-667.

61. Leitzmann MF, Rimm EB, Willett WC, et al. Recreational physical activity and the risk of cholecystectomy in women. N Engl J Med 1999;341:777-784.

62. Broderick-Villa G, Burchette RJ, Collins JC, Abbas MA, Haigh PI. Hospitalization for acute diverticulitis does not mandate routine elective colectomy. Arch Surg 2005;140:576-581.

63. Anaya DA, Flum DR. Risk of emergency colectomy and colostomy in patients with diverticular disease. Arch Surg 2005;140:681-685.

64. Eglinton T, Nguyen T, Raniga S, Dixon L, Dobbs B, Frizelle FA. Patterns of recurrence in patients with acute diverticulitis. $\mathrm{Br} \mathrm{J}$ Surg 2010;97:952-957.

65. Shahedi K, Fuller G, Bolus R, et al. Long-term risk of acute diverticulitis among patients with incidental diverticulosis found during colonoscopy. Clin Gastroenterol Hepatol 2013;11:1609-1613.

66. Salem L, Veenstra DL, Sullivan SD, Flum DR. The timing of elective colectomy in diverticulitis: a decision analysis. J Am Coll Surg 2004;199:904-912.

67. Sharma PV, Eglinton T, Hider P, Frizelle F. Systematic review and meta-analysis of the role of routine colonic evaluation after radiologically confirmed acute diverticulitis. Ann Surg 2014;259:263272.

68. Daniels L, Ünlü Ç, de Wijkerslooth TR, et al. Yield of colonoscopy after recent CT-proven uncomplicated acute diverticulitis: a comparative cohort study. Surg Endosc 2015;29:2605-2613.

69. Lau KC, Spilsbury K, Farooque Y, et al. Is colonoscopy still mandatory after a CT diagnosis of left-sided diverticulitis: can colorectal cancer be confidently excluded? Dis Colon Rectum 2011;54:12651270. 